\title{
A COMPREHENSIVE REVIEW ON ADULTERATION AND SUBSTITUTION OF CRUDE DRUGS PRINCY AGARWAL ${ }^{1 *}$, ANJU GOYAL ${ }^{2}$
}

${ }^{1}$ Department of Faculty of Pharmacy, Bhupal Nobles' University, Udaipur, Rajasthan, India. ${ }^{2}$ Department of Pharmaceutical Chemistry and Quality Assurance, Bhupal Nobles' Institute of Pharmaceutical Sciences, Faculty of Pharmacy, Bhupal Nobles' University, Udaipur, Rajasthan, India. Email: princyagarwal2992@gmail.com

Received: 04 December 2020, Revised and Accepted: 29 January 2021

\section{ABSTRACT}

Herbs are an effective source of Ayurvedic medicine and other traditional medicines as well as modern medicine. Faced with the challenges of modern medicine, the world is shifting toward Ayurvedic theories of health management. In the treatment of the disease, the use of drugs is not limited. This increases the demand for raw materials exponentially. However, production growth is still linear. Rapid depletion of resources creates major problems. To fill the deficit, advances in adulteration and substitution are becoming more prevalent. This adulteration and substitution are a burning problem in an industry that threatens the integrity of Ayurvedic system of medicine. Imprecise knowledge, misidentification, deforestation, and personal gain have led to adulteration. Therefore, an understanding of all ways of adulteration and substitutions is needed to amend this illegal act and maximize consumer safety. This article focuses on adulteration, its types and various methods of adulteration, as well as the concept of substitution, reasoning, and its types. Attempts have also been made to differentiate these two related terms.

Keywords: Adulteration, Substitution, Crude drugs, Ayurveda, Quality assurance, Raw material.

(c) 2021 The Authors. Published by Innovare Academic Sciences Pvt Ltd. This is an open access article under the CC BY license (http://creativecommons.org/ licenses/by/4.0/) DOI: http://dx.doi.org/10.22159/ajpcr.2021v14i4.40452. Journal homepage: https://innovareacademics.in/journals/index.php/ajpcr

\section{INTRODUCTION}

Reliance of human on plants has its roots in the origins of mankind. Shelter, clothing, food, taste and aroma, and finally, medicine constitute the basic necessities of human life. Plants are common medicinal source. The plants have developed a sophisticated traditional healing structure which includes Ayurveda, Unani, and Traditional Chinese [1].

Many health professionals are interested in herbal preparations since more than $70 \%$ of the world's population depends on these as a part of their primary health-care system. In various regions and cultures, herbal medicine is either used as a single herb, a combination of herbs, or a combination of herbs and medicines [2].

Polyherbal formulations are a fundamental traditional therapeutic strategy which utilizes the benefits of the combination of different medicinal herbs to achieve adjunctive therapy, usually known as polypharmacy or polyherbalism.

"Sharangdhar Samhita," an ancient Ayurvedic literature in 1300 A.D. introduced the concept of "Polyherbalism" which comprises combined herbal formulations and herbal extracts. Polyherbal formulations have various active principles and properties that have been used to treat various kinds of human ailments from many centuries. These are a collection of therapies that are formulated and prepared based on the pathogenic properties of each ingredient. These herbal remedies with different pharmacological activities, work together actively to achieve maximum therapeutic benefits with minimal side effects $[2,3]$.

There is a huge delusion among people regarding the safety of Ayurvedic PHFs that these are always safe and does not exhibit any adverse effect. However, Charaka Samhita itself has stated that Ayurvedic medicines have negative effects if they are not properly prepared or used incorrectly [3].

In classical period Vaidyas or Ayurvedic practitioners used to prepare the medicines for the patients by themselves but in today's era this practice got vanished since the production and sale of Ayurvedic drugs have become formalized into a booming industry on a commercial scale being regulated by the Drugs and Cosmetics Act, 1940 [4].
In India, majority of the Ayurvedic PHFs are manufactured and exported. Even though the Drugs and Cosmetic Act have been established to control the manufacture and quality control of Ayurvedic herbal products, the regulations for its production are barely rigorous. The AYUSH Department has also made lots of efforts in issuing good manufacturing practice guidelines and safety standards based on the WHO guidelines, but poor implementation of the same is creating hindrance in adherence to those guidelines. In India, according to Good Clinical Practice, toxicity studies and clinical trials on herbal formulations are not required for the patent application and manufacturer license of Ayurvedic herbal formulations. Due to this various quality related problems such as adulteration, substitution, contamination, and unidentified production shortcuts are becoming more common, leading to incidents such as the presence of synthetic anti-inflammatory drugs in Ayurvedic anti-rheumatic drugs, excessive heavy metal contamination, lack of proper processing, and storage of marketed products in undesirable conditions $[3,5,6]$.

In India, around 9000 licensed units are involved in manufacturing of traditional formulations. At present, the Indian systems of medicine use more than 1100 medicinal plants, most of which are harvested from the wild. More than 60 species are in high demand. The tribal belt of India is rich in these plants and the tribes mainly depend on this trade for their livelihood. There are wide possibilities for adulteration and contamination in the process. Therefore, the adequate availability of adulterant-free quality raw materials at reasonable prices has become a major problem for the industry and the demand is increasing every year [5].

Adulteration and substitution are becoming more common malpractice in raw material trade of medicinal plants. Incorrect identification of many plants and deforestation leading to extinction of many species are some of the factors that have resulted in adulteration and substitution of raw drugs, which have somewhere resulted in decreased faith in herbal drugs. Adulteration in market samples creates hindrance in promotion of herbal products which thereby adversely affected the import and export of these preparations. It has inevitably found that the Adverse Event Reports in adulterated drugs are not because of the intended herb, but rather due to the presence of an unintended herb. In the current scenario, adulteration and substitution of herbal drugs are 
the burning problems faced by the herbal industry. Since most of the raw materials are derived from plant sources and due to adulteration in raw materials and lack of proper standardization techniques for manufacturing, the worldwide acceptance of Ayurveda is becoming problematic $[7,8]$.

Quality standards for medicinal plant materials published by the World Health Organization, recommends rejecting any batch of raw material having more than $5 \%$ of any other plant part of the same plant (e.g., stem in leaf drugs), even though they are derived from the authentic plant. These standards, recommends rejection of adulteration, whether intentional or unintentional and also proposes that suppliers and traders should be educated about the authentic sources.

The future research and development require the pharmacognostic and phytochemical analysis including revaluation of concentration of active phytochemical constituents. It also includes pharmacovigilance as the aspect of the evaluation of medicinal potency, purity, and safety of the final finished goods and products. The stability of the product is also investigated to detect the changes in active phytochemical constituents using their references standards [9].

\section{CRUDE DRUG}

The term crude drug generally applies to the products from plant and animal origin found in a raw form. This term is also used to include drugs from the mineral origin and not necessarily those of organic origin such as kaolin and bentonite.

The term crude drug is referred to the natural product that has not been advanced in value or improved in condition by any process or treatment beyond that which is essential for its proper packing and prevention from deterioration.

Crude drugs are further grouped according to whether they contain a regular organized cellular structure or not, as:

1. Organized drugs: It comprises those crude drug materials which represent a part of the plant and are, therefore, made up of cells.

2. Unorganized drugs: These are a diverse group of solid and liquid materials that do not consist of parts of plants and are obtained from natural sources by a variety of extraction procedures [10].

\section{DRUG ADULTERATION}

"Adulteration" is a broad term having a wide range of interpretations in different places.

\section{Definitions}

1. Adulteration is a practice of substituting the original crude drug partially or fully with other substances which are either free from or are inferior in therapeutic and chemical properties; or addition of low grade or spoiled drugs or entirely different drug similar to that of original drug substituted with the intention of enhancement of profits.

2. Adulteration may also be defined as admixture or substitution of genuine articles with other spurious, inferior, defective, spoiled, useless, other parts of the same or different plant or harmful substances or drug which do not conform with the official standards $[8,11]$.

3. Adulteration means deterioration, admixture, sophistication, substitution, inferiority, and spoilage.

- Deterioration is impairment in the quality of the drug, while,

- Admixture is an addition of one article to another due to ignorance or carelessness or by accident,

- Sophistication is the intentional or deliberate type of adulteration,

- Substitution occurs when some completely different substance is added in place of the original drug,

- Inferiority refers to any substandard drug, and

- Spoilage is due to the attack of microorganisms [10]
An adulterated drug means one which does not conform to the official requirements. The genuine drugs are substituted with spurious, inferior, defective, or harmful substances. Spoiled or deteriorated drugs represent the most significant percentage of cases of drug adulteration [11]

The most prevalent reason for intentional adulteration is typically commercial one and originates mainly with the intention of enhancing profits, followed by some other reasons such as scarcity of drugs and their high market price. In some cases, the adulteration may also occur accidentally. It is also prevalent with contraband drugs [10].

Adulteration may take place broadly by two ways:

(a) Deliberate adulteration

(b) Undeliberate adulteration [11]

\section{DELEBRATE ADULTERATION}

- This is also known as Direct Adulteration or Intentional Adulteration.

This type of adulteration is intentional and usually involves the practice where herbal remedies are partially or entirely replaced by other inferior products, which may have chemical or therapeutic potential. Foreign objects such as stones are also used as an adulterant in crude drugs to increase bulk of the preparation. The adulteration is performed in such a scientific way that it becomes very complicated to trace these adulterations without any microscopic, phytochemical, and physicochemical analysis [12]

(i) With artificially manufactured materials: Which resemble with various drugs in morphological characters as appearance, etc. For example, Nutmeg is adulterated with basswood prepared to the required shape and size; and the colored paraffin wax is used in place of beeswax.

(ii) With inferior quality material: For example, adulteration of senna with dog senna.

(iii) With exhausted materials: Many drugs are extracted on a large scale for the isolation of an active principle, volatile oils, etc. The exhausted material is then used either entirely or in part as a substituent for the genuine drug.

For example, umbelliferous fruits and cloves (without volatile oils) are adulterated with exhausted (without volatile oils) original drugs; exhausted jalap and Indian hemp (without resins) are used as adulterants.

(iv) With foreign matter: Added foreign natter is, of course, cheap in comparison with the cost of the drug.

For example, cochineal (a coloring matter) is adulterated with barium sulfate, barium carbonate, and lead carbonate and myrrh with quarts and other mineral matters.

(v) With fictitious articles: Drugs are sometimes adulterated with worthless non-plant materials which are of no use at all rather harmful sometimes.

For example, pieces of limestone in asafoetida, lead stot in opium, and addition of synthetic benzyl benzoate with Balsam of Peru, etc.

(vi) With excessive adventitious matter: Adulteration involving the presence of an excessive quantity of adventitious materials occurring naturally with the plant.

For example, an excessive amount of stem in lobelia or Datura stramonium leaves.

Undeliberate adulteration

- It is also known as Indirect Adulteration or Un-intentional Adulteration.

It can occur at any time without any bad intentions on the part of the manufacturer or supplier. Various factors affect the quality of the drug, such as geographical sources, growing conditions, processing methods, and storage conditions due to which an adulterated drug may enter the market in the lack of proper evaluation means [12].

This may occur due to the following reasons:

(i) Faulty Collection: Some of the herbal adulterations are due to the carelessness of herbal collectors and suppliers. 
- As in some cases, the proportion of medicinally active constituents reaches a maximum at a particular season, stage of development, or age. However, the collection of the correct parts of genuine/natural plants without regard to time factors causes adulteration. For example, Datura stramonium leaves should be collected during the flowering stage and wild cherry bark in autumn.

- Sometimes adulteration is done by the collection of other less valuable parts of an authentic plant.

For example, in clove, the flower buds are of medicinal importance, but it has been adulterated with flower stalks, which is the less valuable part.

- Collection from other plants by ignorance or neglect or the part of collectors may lead to adulteration, often bearing a superficial resemblance to genuine.

For example, Aconitum deinorrhizum may be collected in place of Aconitum napellus, or Rhamnus california is generally collected in place of Rhamnus purshiana (cascara bark).

(ii) Imperfect Preparation:

- Non-removal of associated structure, for example, stems are collected with leaves.

- Non-removal of inert or undesirable parts or structures, for example, the cork, should be removed from the ginger rhizome.

- Roots and dead portions are collected with rhizomes in the case of male fern.

- Proper drying conditions should be adhered to. Improper drying may lead to undeleberate adulteration. For example, if digitalis leaves are dried above $60^{\circ} \mathrm{C}$, decomposition of glycosides by enzymatic hydrolysis takes place.

- Use of excessive heat in separating the cod liver oil from livers, where the proportion of vitamins, odor, and color, etc., is adversely affected.

(iii) Incorrect storage: The term is self-explanatory. For example,

- Cascara sagrada bark should be collected at least 1 year before being used;

- Belladonna leaves should be stored in moisture-free containers, which, otherwise may result in decomposition of medicinally active constituents due to enzymatic action.

- Volatile oils should be stored in well-closed containers in a cool place, protected from light.

(iv) Gross substitution by plant material: In place of genuine crude drugs, substituted products that are similar in appearance to the genuine are very often sold in the market.

For instance, Ashoka bark is obtained from the plant Saraca indica $L$, while the plant Holorrhena antidysenterica Wall is the source of the drug Kurchi. In the market, however, the barks of Treena orientials Blume and Wrightia Tinctoria $\mathrm{R.} \mathrm{Br}$ are often offered as Ashoka and Kurchi bark, respectively.

(v) Adulteration with non-plant materials: Admixture with non-plant imitation materials bearing a resemblance to a particular drug is also widespread.

For example, adulteration of Clove and Caraway by imitation material made of clay, artificial catechu made of clay and tannin, artificial asafoetida, and synthetic balsam tolu are commonly observed.

(vi) Partial adulteration with other plant materials: Partial adulteration with other similar plant materials is being done by mixing Ailanthus leaves with belladonna; black catechu with aloe; leaves of Digitalis thapsi with $D$. purpurea etc. The official drugs such as Oleo-gum-resin myrrh, gum kino, gum benzoin, balsam tolu are adulterated with different products of similar nature as a matter of routine.

(vii)Substitution of exhausted drug: A classic example of this type of adulteration is provided by used tea leaves, which are collected, dried, sometimes dyed, and mixed with fresh leaves. Similarly, exhausted ginger and liquorice are often mixed with genuine drugs.

Since the process of steam distillation does not in any way change external physical characteristics; therefore, other substances such as cloves, fennel, and caraway, which are used to obtain volatile oil contents, can be easily adulterated/degraded with exhausted ones.

(viii) Confusion in vernacular names: Use of same vernacular name of different species and vice-versa, creates confusion, and invites adulteration. Often in other states, the same plant is known by variety of vernacular names, while quite different drugs are known by the same name, which ultimately leads to confusion.

For example, in Ayurveda, Parpatta refers to Fumaria parviflora. In Siddha, "Parpadagam" refers to Mollugo pentaphylla. Due to the similarity in the names in traditional systems of medicine, these two herbs are often interchanged, or adulterated, or substituted.

(ix) Lack of knowledge about authentic plant sources: This is also one of the common reasons for undeleberate adulteration.

For example, Nagkeshar, that is, Mesua ferrea, is one of the most essential drugs in Ayurveda, but it is adulterated with flowers of Calophyll umindophyllum because suppliers are unaware of it. Nagkeshar is available in parts of the Himalayas and the Western Ghats, which makes it challenging to collect. However, flowers of C. indophyllum are readily available in plains areas, so it is used to replace Nagkeshar.

(x) Morphological similarity: The drugs which look morphologically similar are generally adulterated.

For example, Mucuna prurience is usually adulterated with the Papilionaceae seeds having similarity in morphology.

(xi) Lack of authentic plant: Lack of authentic plant availability, in the required quantity leads to adulteration and substitution.

For example, Hypericum perforatum is cultivated and sold in European markets. In India, Hypericum patulum (Indo-Nepal species) is sold in the name of Hypericum perforatum, since availability of this species is very limited.

(xii) Similarity in color: It is a well-known fact that with the course of time, drug materials get changed to or are substituted with other plant species.

For example, "Ratanjot." In the past, roots of Ventilago madraspatana, was the only source of "Ratanjot," from the Western Ghats. However, due to the similarity in yielding a red dye, Arnebia euchroma var. euchroma is the present source. Ventilago madraspatana is not available in market in recent times.

(xiii)Due to controversial drugs: Controversial drugs or Sandigdha Dravyas are those plants which are mentioned in Ayurveda classics but their botanical identification is not clear. The Ayurvedic and Sanskrit literature has described an herb with many synonyms on the basis of morphology, habitat, origin, therapeutic uses, etc., using different similes, which do not precisely indicate the botanical source, which are leading causes of controversy. Various other causes of controversies are enumerated below:

- Mistake done during copying of manuscripts: Previously, Acharyas and Vaidyas wrote the manuscript manually. During copying, mistakes might have occurred, which, in turn, created controversy.

- Single synonym given for several plants: During the Nighantu periods, the ancient Ayurvedic lexicon used single synonym for two or more than two herbs that are totally different in morphology, causing controversy. For example, Both Tinospora cordifolia (willd.) Miers ex Hook and Thoms and Terminalia chebula Retz. have their name as Amrita.

- Geographical variation: India is a land of diversity; each region has its own diversity of plant species. Hence, as one type was not available, another type was used for the same purpose, which eventually caused controversy. For example, Convulvulus microphyllus Sieb. ex Spreng is used under the name of Sankhpushpi in Northern India but due to geographical variability, it is not available in South and there Clitoria ternatea Linn. is used.

- Poor understanding of Sanskrit words in different contexts: Ayurvedic classics are written mainly in Sanskrit. The same word in different contexts gives different meanings and due to the poor understanding of this type of words controversies arises. For example, Pippala denotes Bodhivriksha when used in male gender and the same in female gender denotes long pepper.

- Substitute leading controversy: Due to non-availability or high cost in the market, there is a possibility of substitution of 
drugs and if this practice continues for a long time, the original identity of a plant may become obscure and the substitute will be considered authentic, which ultimately creates controversy later on.

For example: Pashanbheda, according to its name, is used as urolithiasis (Ashmaribhedana), hence drugs such as Bryophyllum pinnata (Patharchuda) and Aerva lanata Juss are used under the name Pashanbheda. However, Bergenia ligualata (Wall.) Engle was identified as the authentic source of Pashanbheda.

- Parallel evolution of knowledge system: Identifying species and naming them with partially similar or very similar characteristics, the inherent qualities of accent and dialects can create controversy. For example, Brahmi is mentioned in Ayurveda classics as brain tonic. Mandukparni is another medicine which is called Medhya Rasayan (brain tonic) in Charaka Samhita. Bacopa monnieri (L.) Pennel, is the source for Brahmi but in Northern India Centella asiatica (L) urban (Mandookparni) is called as Brahmi due to similarity in therapeutic effects.

- Vernacular names: Synonyms are also given to plants based on local languages, which sometimes also causes confusion in the naming systems of various plants with similar names. For example, Matala in Tamil refers to Punica granatum Linn., while in Kannada it refers to Citrus medica.

- Non-Ayurvedic literature also creates controversy: In poetry Kamala, Utpala, Kumuda, Kalhara, all represents the same plant lotus, but botanically they are different species. [8,10,11,13-18]

\section{Methods used for adulteration}

The methods used for adulteration may be grouped as follows:

\section{Manufacture of substitutes}

Materials are artificially manufactured to simulate the general form and appearance of various drugs.

For example, Nutmegs have been similarly imitated by cutting basswood pieces to the required shape or by molding a mixture of clay and leguminous meal. Coffee also has been replicated by compressing powdered chicory to the form of coffee berries. Paraffin wax colored yellow has been substituted for beeswax and artificial invert sugar for honey.

\section{Substitution with substandard commercial varieties}

The adulterants used here may resemble original crude drug by morphological, chemical, or therapeutic characters but are substandard in nature and hence are cheaper. This is instead the most common practice of adulteration.

The examples are Indian senna substituted with Arabian senna and dog senna; gentian substituted by kutki; medicinal ginger replaced by its inferior varieties; African, Japanese, and Cochin ginger.

\section{Substitution with exhausted drugs}

In this type, the same drug is admixed but does not have any therapeutically active constituents because these are already extracted out. This practice is more common in volatile essential oils that contain drugs such as fennel, clove, coriander, and caraway. Sometimes, natural characters such as color and taste of exhausted drugs are manipulated using various additives and then these are substituted.

For example, exhausted gentian made bitter with aloes; the artificial coloring of exhausted saffron.

Substitution of superficially similar but cheaper natural substances, usually having no relation to the genuine article

The cheaper substances are being used due to the morphological resemblance to the authentic drug, and may or may not have any chemical or therapeutic value compared to the original drug.
For example, Belladonna leaves are substituted with Ailanthus leaves; saffron is admixed with dried flowers of Carthamus tinctorius; mother cloves and clove stalks are mixed with clove; and beeswax is substituted by Japanese wax.

\section{Harmful adulterants}

In case of liquids or unorganized drugs, it has been observed several times that wastes are collected from the market and admixed with authentic drugs.

For example, pieces of amber colored glass in colophony, limestone in asafoetida, lead shot in opium, white oil in coconut oils. The addition of rodent fecal matter to cardamom seeds is a very harmful adulterant.

\section{Addition of synthetic principles to fortify inferior products}

Besides above mentioned common practices, sometimes other methods are also employed like use of synthetic chemicals to enhance the potential characteristics of the crude drugs.

For example, addition of benzyl benzoate to balsam of Peru, Citral to citrus oils likes oil of lemon and orange oil.

\section{Presence of vegetative matter from the same plant}

Sometimes, the other miniature plants growing along with the medicinal plant or the vegetative parts of the same plant are mixed with the crude drug, due to their resemblance in color, odor, and in some cases, the constituents.

For example, the lower plants such as moss, liverworts, and epiphytes growing on bark portion are mixed with cascara or cinchona crude drugs. The stem portions are mixed along with leaves of drugs such as stramonium, lobelia, and senna.

\section{Adulteration of powders}

Apart from the whole drugs, the powdered forms of the crude drugs are more frequently found to be adulterated.

Some examples include, dextrin in ipecacuanha; powdered liquorice or gentian admixed with powdered olive stones; exhausted ginger powder in powdered colocynth or ginger; and red sanders wood in capsicum $[10,11,19]$.

\section{SUBSTITUTION}

From a Pharmacognostic point of view, substitution refers to the replacement with an entirely different article that can be used or sold in place of the desired one having relatively the same characteristics. For example, the roots, stems, and stem bark of the drug plant Coscinium fenestratum (Gaertn.) Colebr. (Menispermaceae) are being used in the Indian crude drug market as a substitute for the root, root bark, and stem of the drug plant Berberis aristata DC (Berberidaceae) for many years [20].

In simple terms, substitution involves the replacement of analogous drugs having equivalent pharmacological effects and therapeutic activities instead of original drugs. In Ayurveda, substitution is discussed under the term Abhava Pratinidhi Dravya. Acharya Vagbhata gave the concept of substitution in later periods, as this concept did not exist during the Samhita period. He stated that one should get another drug having similar essential characteristics as that of the original one if there is unavailability or lack of the latter. The principles to select substitute drugs are based on equivalency of five basic tenets, namely, Ras (taste), Guna (characteristic), Veerya (potency), Vipaka, and most importantly, Karma (therapeutic action).

A detailed account of Pratinidhi Dravyas can be obtained from ancient textbooks such as Bhavaprakasha (authored by Bhavamishra, $16^{\text {th }}$ century), Yogaratnakara (17 $7^{\text {th }}$ century), and Bhaishajya ratnavali (authored by Govind Das, $14^{\text {th }}$ century) $[7,17]$. 


\section{Rationale for substitution}

\section{Non-availability of the drug}

In case of non-availability of a particular drug, it can be substituted by other drugs with similar therapeutic effects. For example, in Astavarga (a group of eight crude drugs), Meda and Mahameda are substituted by Shatavari.

\section{Cost of the drug}

This is one of the most prominent reasons. Most of the herbal formulations are very costly, and substitution often leads to the reduced price of the preparation, making it affordable for the buyer. For example, Kumkuma (Crocus sativus) is very expensive; therefore, it is substituted by less expensive Kusumbha (Carthamus tinctorius Linn.)

\section{Uncertain identity of the drug}

The drugs with not much well-defined botanical identity are generally substituted by known ones. For example, for the herb Lakshmana, different species such as Aralia quinquefolia and Ipomea sepiaria are used.

\section{Adverse reaction of the drug}

It has been observed that many times, a drug exhibits various adverse reactions which make it necessary to be substituted. For example, Vasa (Adhatoda vasica) is a good Rakta-Pittahara (antihemorrhagic) drug, but have abortifacient activity, so instead of this drug Laksha (Lacifer lacca), Ashoka (Saraca asoka) are used in pregnant women for the same purpose.

\section{Shelf life of the drug}

Shelf life of the drug is also another reason for the substitution. For example, in case of non-availability of old jaggery, new jaggery can be used after heating in sun rays for four hours.

\section{Seasonal availability of drugs}

Most of the crude drugs are available seasonally, due to which these are not available throughout the year. Therefore, other available drugs with similar actions are used. For example, Punarnawa (Boerhaavia diffusa) is commonly not available throughout the year; so for that, Trianthema portulacastrum (Varshabhu) can be used as a substitute, which is available throughout the year.

\section{Geographical distribution of the drug}

Different drugs are considered sources according to the geographical distribution and availability of a particular drug. For example, Rasana is a herb with multiple therapeutic uses but has different sources depending on geographical distribution. In Northern India, Pluchea lanceolata is used whereas in southern parts, Alpinia galanga is used, and in Bengal, Vanda roxburghii is considered a source of Rasana [15,17].

\section{Types of substitution}

Substitution can be performed in several ways:

1. Substitution with a totally different drug: For example, Bharangi (Clerodendron indicum) and Kantakari (Solanum xanthocarpam) are commonly used as a substitute for one another in diseases related to the respiratory system. Both have different rasa and guna but have similar therapeutic effects.

2. Substitution with species belonging to the same family: For example, Datura metal is generally substituted by Datura stramonium in the treatment of respiratory tract disorders.

3. Substitution with substances belonging to different species: For example, two types of Gokshura are used alternatively; they are: Laghu Gokshur - Tribulus terrestris (Zygophyllaceae) and Brihat Gokshura - Padalium murex (Pedaliaceae) since both the species are proved for Nephroprotective, Lithotriptic, Diuretic, and Hepatoprotective activities.

4. Substitutions with different parts of the same plant: For example, the roots of Sida cordifolia are mentioned as an official part in the
Ayurvedic classics. Still, instead of roots, whole plants of $S$. cordifolia are used.

5. Substitution with substances having similar action: For example, Amalaki (Emblica officinalis) can be taken instead of Bhallatak (Semicarpus anacardium) for Rasayan karma (rejuvenating action) [7,17].

Difference between adulteration and substitution [7]

\begin{tabular}{lll}
\hline S. No. & Adulteration & Substitution \\
\hline 1 & $\begin{array}{l}\text { Adulteration is a } \\
\text { deliberate addition of } \\
\text { foreign substances to } \\
\text { increase the weight of a } \\
\text { product and lower its cost. } \\
\text { Put simply; adulteration is } \\
\text { the vitiation of an article. }\end{array}$ & $\begin{array}{l}\text { Instead, it is a drug based on } \\
\text { similar properties such as } \\
\text { Rasa, Guna, Virya, and Vipaka, } \\
\text { and last but not least is Karma. }\end{array}$ \\
& $\begin{array}{l}\text { Substitution is usually } \\
\text { performed when the original } \\
\text { medicines are not available } \\
\end{array}$ & $\begin{array}{l}\text { or are lacking in sufficient } \\
\text { quantities. }\end{array}$ \\
& & Vaidya named the substitution \\
& It is added in part or in & drugs as Pratinidhi Dravyas.
\end{tabular}

or inadequate in terms of

medicinal and chemical properties.

$4 \quad$ It involves the addition of lower standards or spoiled or completely different drugs having a resemblance with the original drugs.

5 The aim is to increase profits.

Adulterants are similar to crude drugs in morphology but inferior in nature and cheaper in cost.

7 Adultery is also done with synthetic materials.

8 Adulteration results in various undesirable adverse effects.

Sometimes, the adulterated products may be devoid of therapeutic activity.

\section{Criteria of GMP rules and act under schedule -T for ASU drugs}

As per Indian Drugs and Cosmetics Act 1940 (23 of 1940) and the Drugs and Cosmetics Rules, 1945 [As amended up to the December 31, 2016], under Chapter-IVA namely- Provisions Relating to Ayurvedic Siddha and Unani Drugs for mandatory controlling rules of ASU drugs, following are the definitions for explaining the Adulterant or substituted and spurious drugs:

1. 33EE. Adulterated drugs. For the purposes of this Chapter, an Ayurvedic, Siddha, or Unani drug shall be deemed to be adulterated-

(a) if it consists, in whole or in part, of any filthy, putrid, or decomposed substance; or

(b) if it has been prepared, packed, or stored under insanitary conditions whereby it may have been contaminated with filth or whereby it may have been rendered injurious to health; or

(c) if its container is composed, in whole or in part, of any poisonous or deleterious substance which may render the contents injurious to health; or

(d) if it bears or contains, for purposes of coloring only, a color other than one which is prescribed; or 
(e) if it contains any harmful or toxic substance which may render it injurious to health; or

(f) if any substance has been mixed therewith so as to reduce its quality or strength.

Explanation.-For the purpose of clause (a), a drug shall not be deemed to consist, in whole or in part, of any decomposed substance only by reason of the fact that such decomposed substance is the result of any natural decomposition of the drug:

Provided that such decomposition is not due to any negligence on the part of the manufacturer of the drug or the dealer thereof and that it does not render the drug injurious to health.

2. 33EEA. Spurious drugs.-For the purposes of this Chapter, an Ayurvedic, Siddha, or Unani drug shall be deemed to be spurious-

(a) If it is sold, or offered or exhibited for sale, under a name which belongs to another drug; or

(b) If it is an imitation of, or is a substitute for, another drug or resembles another drug in a manner likely to deceive, or bears on it or on its label or container the name of another drug, unless it is plainly and conspicuously marked so as to reveal its true character and its lack of identity with such other drug; or

(c) If the label or container bears the name of an individual or company purporting to be the manufacturer of the drug, which individual or company is fictitious or does not exist; or

(d) If it has been substituted wholly or in part by any other drug or substance; or

(e) If it purports to be the product of a manufacturer of whom it is not truly a product [21].

\section{CONCLUSION}

Counterfeiting and substitution are intertwined and create problems for the standardization of Ayurvedic practice and herbal medicine. The prospect can be intentional or accidental. To determine and detect adulteration, various stages of drug evaluation need to be carried out. Intentional adulteration must be stopped by enforcing strict rules. The main element for resolution is the correct authentication of the medicinal plant sources mentioned in the classics. For this reason, it is necessary to conduct literature studies, ethnographic research, the study of medicinal plants, and evaluation of medicinal products (morphological, microscopic, chemical, physical, and biological assessments).

With more than 300 medicinal plants on the red list and due to the lack of indigenous medicines because of deforestation, global warming, lack of proper cultivation methods, etc., the substitution of the herbs and herbal medicine is needed today. The essential criterion for substitution is the pharmacological activity rather than the morphology or phytochemical constituents. This has to be justified in modern times using Ayurvedic principles and modern scientific tools. Today, the Ayurvedic pharmaceutical industry adheres to high-quality standards with modern technologies and equipment to maintain its quality.

After understanding adulteration methods, further research and information are needed to correct and minimize illegal adulteration to improve consumer safety. For this purpose, a review of scientific literature, expert opinion, pharmacology, kinetics/dynamics, interactions, side effects, toxicology, and dosage, etc., could be a great help. Reports of adverse health effects and plant-related deaths, widespread distribution, and sale of counterfeit products, and an apparent increase in misleading promotional claims on the internet require urgent action to protect public health. It is impossible to provide adequate healthcare without guaranteed quality drugs. To provide safe and effective healthcare, it is necessary to ensure the quality of medicines.

\section{CONFLICT OF INTEREST}

None.

\section{REFERENCES}

1. Aslam MS, Ahmad MS, Mamat AS, Ahmad MZ, Salam F. An update review on polyherbal formulation: A global perspective. Syst Rev Pharm 2016;7:35-41.

2. Barik CS, Kanungo SK, Tripathy NK, Panda JR, Padhi M. A review on therapeutic potential of polyherbal formulations. Int J Pharm Sci Drug Res 2015;7:211-28.

3. Parasuraman S, Thing GS, Dhanaraj SA. Polyherbal formulation: Concept of ayurveda. Pharmacogn Rev 2014;8:73-80.

4. Modha J. Adverse Drug Reaction of Ayurveda Medicines; 2010 Available from: https://www.boloji.com/articles/1103/adverse-drugreaction-of-ayurveda-medicines. [Last accessed on 2020 Oct 09].

5. Patwardhan B, Warude D, Pushpangadan P, Bhatt N. Ayurveda and traditional Chinese medicine: A comparative overview. Evid Based Complement Altern Med 2005;2:465-73

6. Munshi R, Bhalerao S, Kalekar S. Proceedings. J Ayurveda Integr Med 2012;3:168-72.

7. Neelam, Kumar N, Dwivedi KN, Ram B. Adulteration and substitution of medicinal plant: A burning problem in herbal industry. Int J Pharm Biol Arch 2014;5:13-8

8. Kurele R, Rohit KS, Pawar G, Abdulah, Singh J, Srinivasulu B. A comprehensive review on adulteration of raw materials used in ASU drug. Int J Ayurveda Pharm Res 2018;6:66-71.

9. Sagar PK. Adulteration and substitution in endangered, ASU herbal medicinal plants of india, their legal status, scientific screening of active phytochemical constituents. Int J Pharm Sci Res 2014;5:4023-39.

10. Kokate CK, Purohit AP, Gokahle SB. Pharmacognosy. 54 ${ }^{\text {th }}$ ed. Pune: Nirali Prakashan; 2017. p. 1-9.

11. Ansari SH. Essentials of Pharmacognosy. $7^{\text {th }}$ ed. Delhi: Birla Publications Private Ltd.; 2018. p. 10-12.

12. Poonam. Adulteration of crude drugs burning problem. Int $\mathbf{J}$ Appl Res 2016;2:99-101.

13. Prakash O, Jyoti, Kumar A, Kumar P, Manna NK. Adulteration and substitution in indian medicinal plants. J Med Plants Stud 2013;1:127-32.

14. Mohammad A. Textbook of Pharmacognosy. $2^{\text {nd }}$ ed. New Delhi: CBS Publishers and Distributors Private Ltd.; 2018. p. 43-51.

15. Snehal S, Anand T, Mukund D, Kavita D. Adulteration and need of substitution of raw materials - a review. Int J Ayurveda Pharm Res 2018;6:92-5

16. Qadry J. A Textbook of Pharmacognosy: Theory and Practicals. $16^{\text {th }}$ ed. New Delhi: CBS Publishers and Distributors Private Ltd.; 2019. p. 29-30.

17. Keshari P, Pradeep. Controversy, adulteration and substitution - burning problems in ayurveda practices. Int Ayurvedic Med J 2017;5:2504-16.

18. Gupta M, Sharma P. Textbook of Pharmacognosy. $1^{\text {st }}$ ed. Meerut: Pragati Prakashan; 2009. p. 174-7.

19. Ahmed S, Hasan M. Crude drug adulteration: A concise review. World J Pharm Pharm Sci 2015;4:274-83.

20. Selvam $A B$. Is the term substitution relevant to pharmacognosy and/ or vegetable crude drug industry? Pharmacogn Res 2010;2:323-4.

21. Anonymous. The Drugs and Cosmetics Act, 1940 and Rules, 1945 as Amended up to the $31^{\text {st }}$ December, 2016. Ch. 4. New Delhi: Government of India, Ministry of Health and Family Welfare; 2016. p. 27-8. 